\title{
Lamellar-forming grain boundary reaction related to age-hardening mechanism in an Au-Pt-Pd-In metal-ceramic alloy
}

\author{
Sung-Min Kim • Hyung-Il Kim • Byung-Wook Jeon • \\ Yong Hoon Kwon • Hyo-Joung Seol
}

Published online: 9 July 2014

C The Author(s) 2014. This article is published with open access at SpringerLink.com

\begin{abstract}
This study examined the relationship between the lamellar-forming grain boundary reaction and the change in hardness during the aging process of an $\mathrm{Au}-$ Pt-based metal-ceramic alloy composed of $76.6 \mathrm{Au}-9.9$ Pt-9.3 Pd-1.7 In-1.2 Ag-0.56 Sn (wt\%) with minor ingredients. The phase decomposition of the parent Au-rich $\alpha$ phase occurred within a very short time $(30 \mathrm{~s})$ by aging at $550{ }^{\circ} \mathrm{C}$ after a solution-treatment at $950{ }^{\circ} \mathrm{C}$ due to the solubility limits of $\mathrm{Au}$ and $\mathrm{Pt}$ in each other, which initiated a lamellar-forming grain boundary reaction. The observed hardening was attributed to both the grain interior and grain boundary precipitate. On the other hand, the grain boundary precipitate comprising the fine lamellar structure caused more powerful hardening from the early stage of the aging process. The alternate layer of the grain boundary lamellar structure was composed of Pt-, In- and Sn-depleted Au-rich $\alpha_{1}$ phase as well as precipitated Pt-, In- and Sn-concentrated $\beta_{1}$ phase. The extremely fine nature of the grain boundary lamellar structure supplied large amounts of inter-phase boundaries, which contained lattice strain by the difference in the lattice parameter between the $\alpha_{1}$ and $\beta_{1}$ phases, resulting in hardening.
\end{abstract}

Keywords Lamellar-forming grain boundary reaction . Age-hardening · Au-Pt-Pd-In metal-ceramic alloy . Precipitation

S.-M. Kim• H.-I. Kim • B.-W. Jeon • Y. H. Kwon • H.-J. Seol ( $₫)$ Department of Dental Materials, Institute of Translational Dental Science, School of Dentistry, Pusan National University, Beomeo-Ri, Mulgeum-Eup, Yangsan-Si, Gyeongsangnam-Do 626-814, South Korea

e-mail: seolhyojoung@daum.net

\section{Introduction}

Metal-ceramic restorations are still the most reliable methods in dental prosthetics, and a range of metal-ceramic alloys is used in dentistry [1]. Among the others, dental gold alloys for metal-ceramic restorations consist basically of $\mathrm{Au}$ and $\mathrm{Pd}$ as the principle ingredients, as well as $\mathrm{Pt}, \mathrm{Ag}, \mathrm{Sn}$, In and $\mathrm{Fe}$ as minor ingredients. Metal-ceramic alloys based on $\mathrm{Au}$ are hardened substantially by an appropriate heat treatment to resist the occlusal force in the oral environment [2, 3]. Minor ingredients, such as Pt, Sn, In and Fe, play important roles in precipitation hardening $[4,5]$.

In dental alloys hardened by precipitation, lamellar structures are normally observed in the grain boundaries [6-11]. These lamellar-forming grain boundary reactions were reported to be the mechanism for softening in most cases and sometimes for hardening depending on the alloy composition [6-11]. In a study with a dental casting alloy composed of $48.78 \mathrm{Ag}-28 \mathrm{Pd}-12.04 \mathrm{Au}-9.12 \mathrm{Cu}$ (wt\%), the lamellar structure that formed by the first grain boundary reaction resulted in hardening, but the second grain boundary reaction produced a very coarse lamellar structure that resulted in softening [6]. In a study with a dental casting alloy composed of 47.5 Au-36 Ag-10.6 Cu-4 Pd-1 In-0.7 Zn-0.2 Ir (wt\%), the formation of a grain boundary lamellar structure resulted in softening [11]. In the case of Pt-added-Au-based alloy for metal-ceramic restorations, precipitation hardening can occur by an appropriate heat treatment due to the solubility limits of $\mathrm{Au}$ and Pt in each other [12-14]. Therefore, the hardness of the alloy can be changed by lamellar formation during the firing process for porcelain. To use the Pt-added-Au-based metal-ceramic restoration under the best mechanical condition, it is important to determine the relationship between the lamellar-forming grain boundary reaction and the change in hardness. On the other hand, it is unclear if the lamellar- 
forming grain boundary reaction is the mechanism for hardening or softening in the Pt-added-Au-based metal-ceramic alloy [15]. This study examined the relationship between the lamellar-forming grain boundary reaction and the change in hardness during the aging process of a Pt-added-Au-based metal-ceramic alloy composed of $76.6 \mathrm{Au}-9.9 \mathrm{Pt}-9.3 \mathrm{Pd}-$ 1.7 In $(w t \%)$ with minor ingredients by hardness testing (HV), X-ray diffraction (XRD), field emission-scanning electron microscopy (FE-SEM) and energy-dispersive spectrometry (EDS).

\section{Materials and methods}

Specimen alloy

The specimen used in this study was a dental high-carat gold alloy (AURIUM 3, Aurium ${ }^{\circledR}$ Research USA, San Diego, CA, USA) of type III-IV according to the ISO classification (ISO 22674:2006 (E)). This type of alloy is based on the ternary system of $\mathrm{Au}, \mathrm{Pt}$ and $\mathrm{Pd}$ for the fabrication of metal-ceramic prostheses. Table 1 lists the chemical composition of the specimen alloy supplied by the manufacturer, where only the minor ingredients that comprised less than $1 \mathrm{wt} \%$ were examined by X-ray fluorescence analysis (XRF) to determine the precise content.

\section{Heat treatment}

The specimens were subjected to a solution treatment at $950{ }^{\circ} \mathrm{C}$ for $10 \mathrm{~min}$ in a vertical furnace in an argon atmosphere to obtain a supersaturated solid of a single phase. The specimens were then quenched in ice brine to prevent the formation of an equilibrium phase. Subsequently, the solution-treated specimens were subjected to isothermal aging at $550{ }^{\circ} \mathrm{C}$ for various times in a molten salt bath $\left(25 \mathrm{KNO}_{3}+30 \mathrm{KNO}_{2}+25\right.$ $\mathrm{NaNO}_{3}+20 \mathrm{NaNO}_{2}, \mathrm{wt} \%$ ) and quenched in ice brine.

\section{Hardness test}

To examine the hardening and subsequent softening mechanism during the aging process, the hardness of the heat-treated plate specimens was measured using a Vickers microhardness tester (MVK-H1, Akashi Co., Akashi, Hyogo Japan) using a 25- or 300-gf load and a holding time of $10 \mathrm{~s}$. The values reported are the mean of five measurements.
XRD study

XRD (X'PERT PRO, PRO, Philips, Eindhoven, Netherlands) was performed to examine the phase transformation during the aging process. Powder specimens with a particle size below $45 \mu \mathrm{m}$ were filed using a diamond disc and passed through a 330-mesh screen. The specimens were then mixed with alumina powders with a particle size of $1 \mu \mathrm{m}$ to prevent sintering agglomeration during heat treatment. Subsequently, the powder specimens were subjected to vacuum sealing in silica tubes and heat treatment. The alumina powders were then filtered from the heat-treated specimens. The XRD profile was recorded at $30 \mathrm{kV}$ and $40 \mathrm{~mA}$ using Ni-filtered $\mathrm{Cu} \mathrm{K} \alpha$ radiation as the incident beam.

\section{FE-SEM observation}

FE-SEM image of the heat-treated plate specimens was taken to examine the microstructural changes during the aging process. The heat-treated specimens were treated with a polisher and etched in an aqueous solution containing $10 \% \mathrm{KCN}$ (potassium cyanide) and $10 \%\left(\mathrm{NH}_{4}\right)_{2} \mathrm{~S}_{2} \mathrm{O}_{8}$ (ammonium persulfate). The surfaces of the heat-treated specimens were observed by FE-SEM (JSM-6700 F, Jeol, Akishima-shi, Tokyo, Japan) at $15 \mathrm{kV}$.

EDS analysis

The EDS (INCA X-Sight, Oxford instruments Ltd., Oxford, UK) profiles of the heat-treated plate specimens were recorded at $15 \mathrm{kV}$ to determine the changes in the elemental distribution during the aging process. The specimens were prepared in the same manner as used for the FE-SEM observations.

\section{Result and discussion}

Age-hardening behaviour

To determine the most effective aging temperature, which is related to age-hardening behaviour, the plate-like specimens, which were solution-treated at $950{ }^{\circ} \mathrm{C}$ for $10 \mathrm{~min}$, were aged isochronally over the temperature range of $300-630{ }^{\circ} \mathrm{C}$ for $20 \mathrm{~min}$. The microhardness was measured using a 300-gfload. Figure 1 shows the isochronal age-hardening curves of the specimen aged over the temperature range of 300 to $630{ }^{\circ} \mathrm{C}$ for $20 \mathrm{~min}$. The specimen showed apparent age-hardenability
Table 1 Chemical composition of the specimen alloy

\begin{tabular}{llllllllll}
\hline Composition & $\mathrm{Au}$ & $\mathrm{Pt}$ & $\mathrm{Pd}$ & $\mathrm{In}$ & $\mathrm{Ag}$ & $\mathrm{Sn}$ & $\mathrm{Cu}$ & $\mathrm{Ir}$ & $\mathrm{Fe}$ \\
\hline wt\% & 76.6 & 9.9 & 9.3 & 1.7 & 1.2 & 0.56 & 0.3 & 0.27 & 0.17 \\
at.\% & 68.61 & 8.95 & 15.42 & 2.61 & 1.96 & 0.83 & 0.83 & 0.25 & 0.54 \\
\hline
\end{tabular}


Fig. 1 Isochronal age-hardening curves of the specimen aged at temperature ranging from 300 to $630{ }^{\circ} \mathrm{C}$ for $20 \mathrm{~min}$

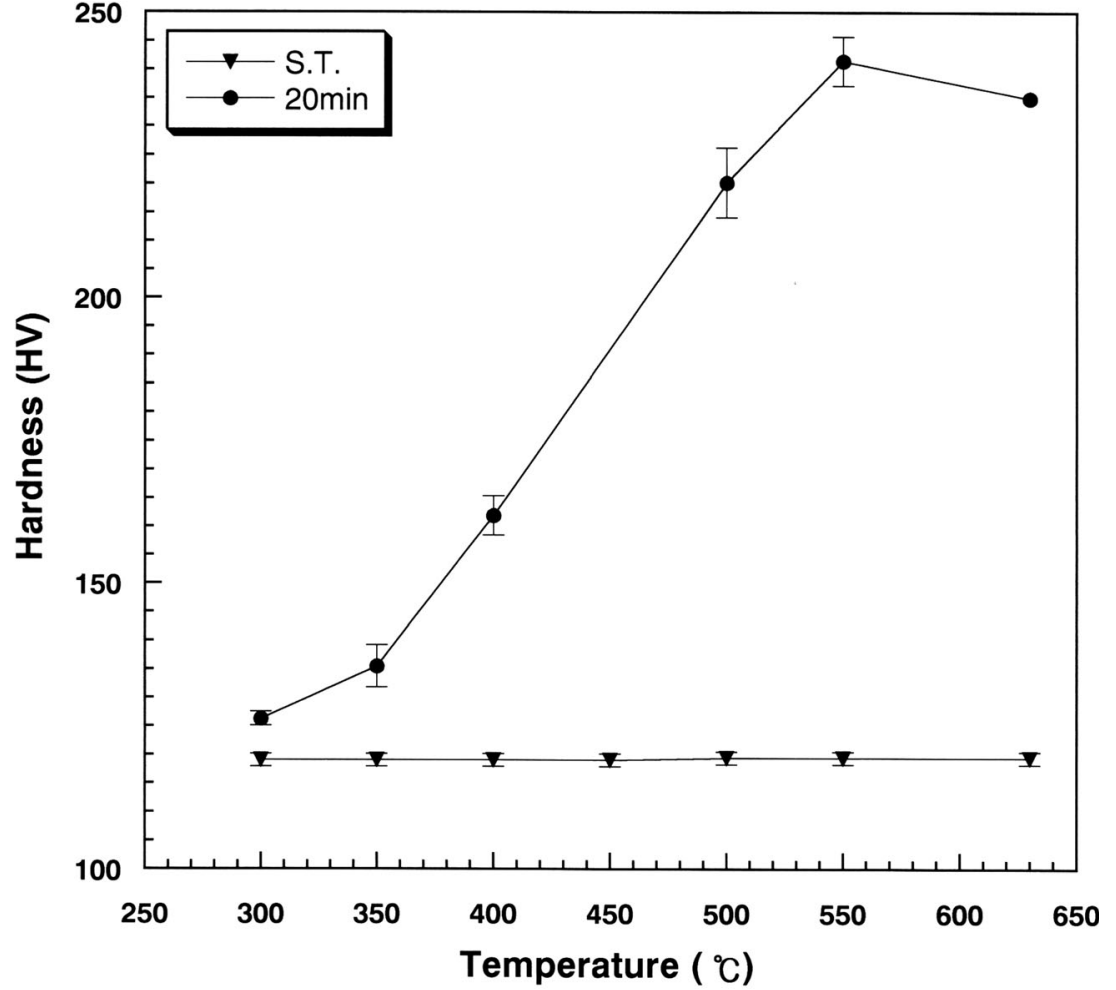

at an aging temperature of $550{ }^{\circ} \mathrm{C}$. Therefore, the isothermal age-hardening behaviour was observed at $550{ }^{\circ} \mathrm{C}$ to evaluate the age-hardenability of the specimen.

Figure 2 shows the isothermal age-hardening curve of the specimen solution-treated at $950{ }^{\circ} \mathrm{C}$ for $10 \mathrm{~min}$ and then aged at $550{ }^{\circ} \mathrm{C}$ for various times until $20,000 \mathrm{~min}$. The microhardness was measured using a 300-gf load without dividing the grain interior and grain boundary. The hardness obtained at 2 min was approximately two times higher than that of the solution-treated condition. Thereafter, the hardness increased
Fig. 2 Isothermal age-hardening curve of the specimen aged at $550{ }^{\circ} \mathrm{C}$

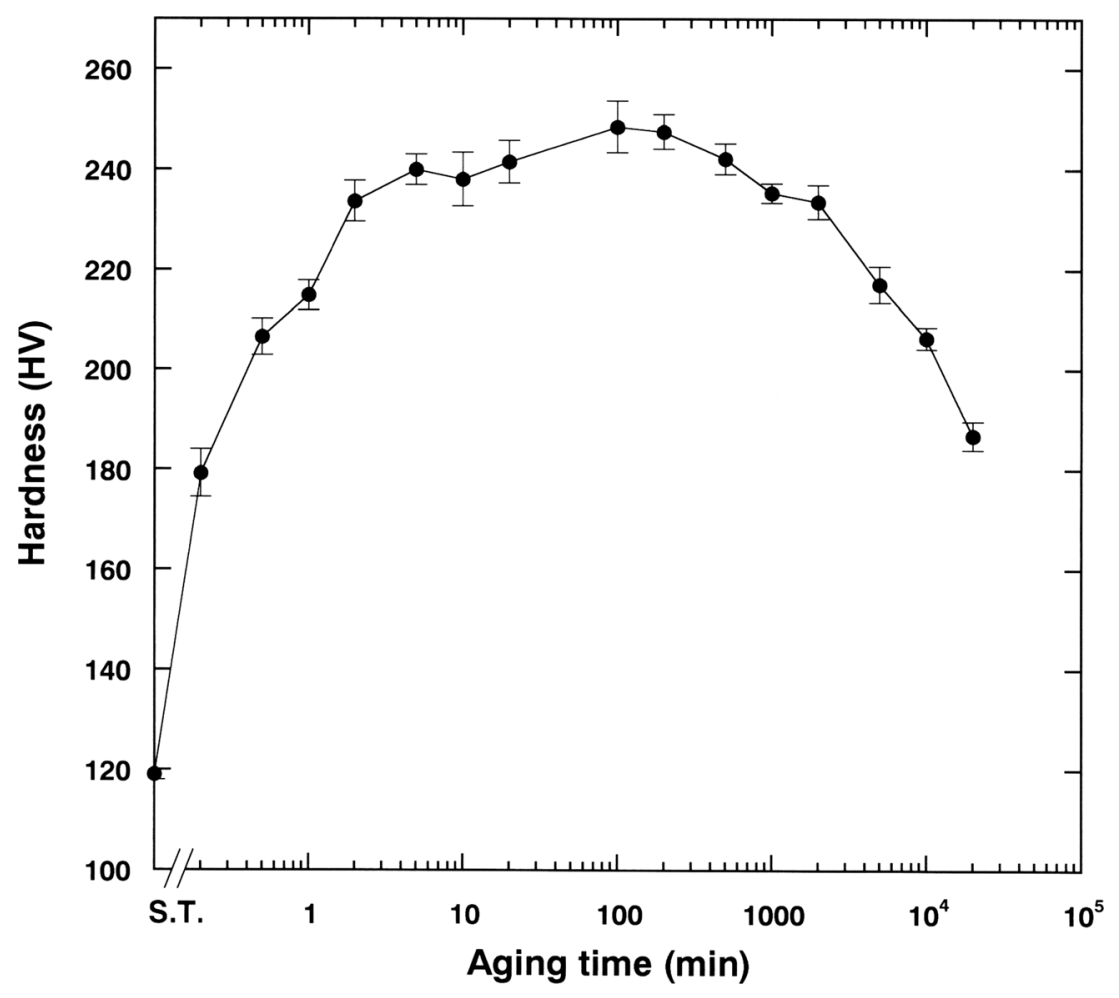


gradually with aging time and reached a maximum at $100 \mathrm{~min}$. After maintaining the maximum value until $200 \mathrm{~min}$, the hardness decreased gradually until 2,000 min and then decreased apparently until 20,000 min.

Phase transformation

The variations of the XRD patterns during isothermal aging were examined to clarify the relationship of the phase transformation and hardness change in the early and later stage of the aging process. Figure 3 presents the variations of the XRD patterns of the specimens solution-treated at $950{ }^{\circ} \mathrm{C}$ for $10 \mathrm{~min}$ and then aged at $550{ }^{\circ} \mathrm{C}$ for various times until $20,000 \mathrm{~min}$. The XRD pattern of the solution-treated (S.T.) specimen showed a single Au-rich $\alpha$ phase with a face-centred cubic (f.c.c) structure and a lattice parameter of $a_{200}=4.0222 \AA$. This value was slightly smaller than the reported lattice parameter of $\mathrm{Au}(a=4.0786 \AA)$ [16]. In the XRD pattern of the specimen aged at $550{ }^{\circ} \mathrm{C}$ for $30 \mathrm{~s}$, the $(111,200) \alpha$ diffraction peaks broadened asymmetrically to the lower diffraction angle side. And, weak diffraction peak in the higher diffraction angle side of the main peak was observed. Therefore, the phase decomposition of the parent $\alpha$ phase was initiated within $30 \mathrm{~s}$, resulting in an apparent increase in hardness by $100 \mathrm{HV}$, as shown in Fig. 2.

By prolonged aging until 20,000 min, the XRD patterns did not show further changes. The asymmetrical shape of the main peaks resulted mainly from peak overlap of the solute-
Fig. 3 Variation of the XRD patterns of the specimens during isothermal aging at $550{ }^{\circ} \mathrm{C}$ with aging time

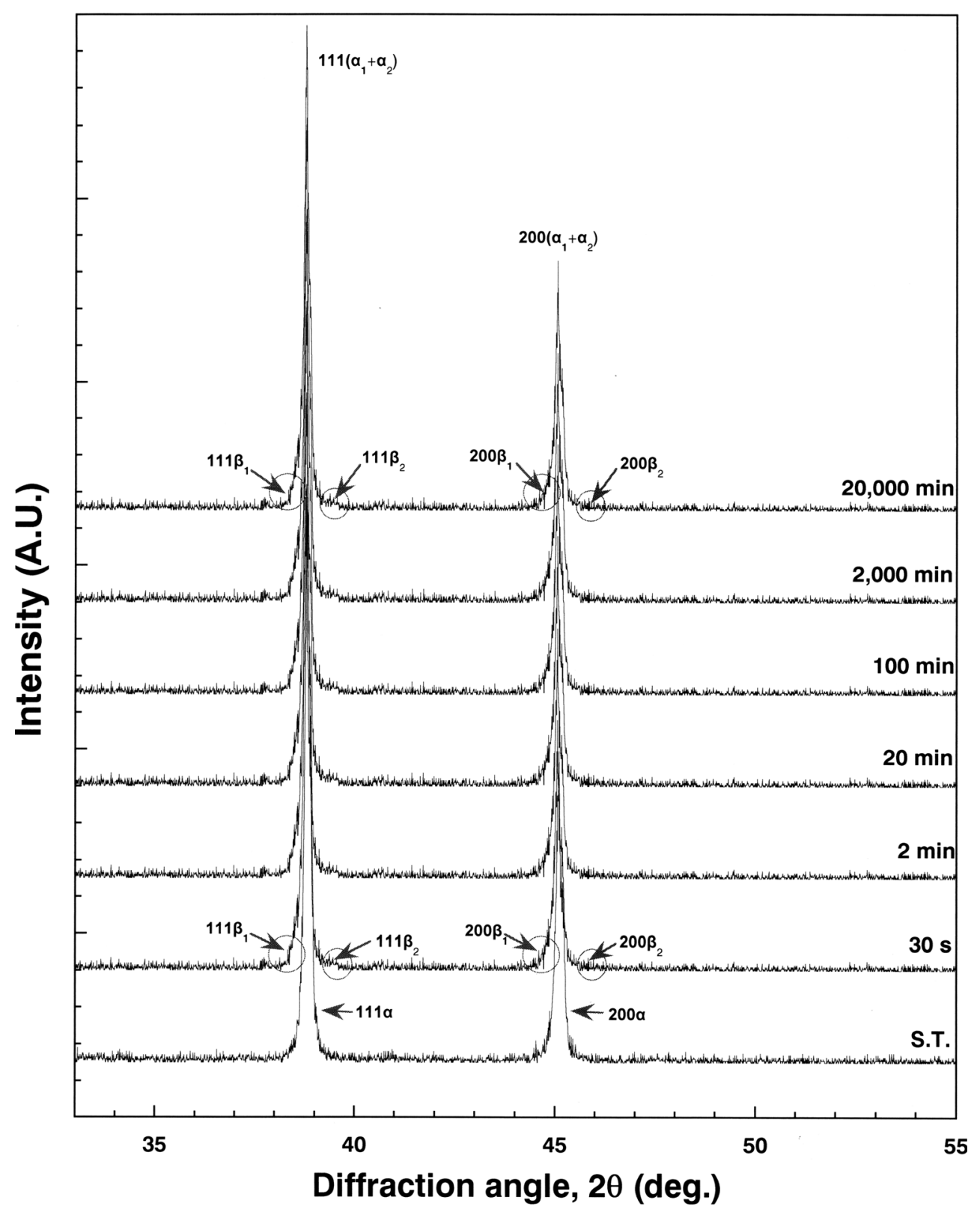


depleted parent phase and precipitated phase $\left(\beta_{1}\right)$ due to the small gap in the lattice parameters. The weak diffraction peak in the higher diffraction angle side of the main peak was from the f.c.c $\beta_{2}$ phase which had the lattice parameter, $a_{200}=$ $3.986 \AA$. This value was very similar to the lattice parameter of the $\mathrm{Pt}_{3} \mathrm{In}$ phase, $a=3.992 \AA$ [17]. The lattice parameter of the parent Au-rich $\alpha$ phase showed little change from $a_{200}=$ $4.0222 \AA$ to $a_{200}=4.0231 \AA$ by a transformation into the solute-depleted Au-rich phases $\left(\alpha_{1}+\alpha_{2}\right)$. This will be further mentioned in elemental distribution part.

The specimen used in this study was a gold alloy containing approximately $9 \mathrm{wt} \% \mathrm{Pd}$ and $\mathrm{Pt}$, respectively. The alloy composed of only $\mathrm{Au}$ and $\mathrm{Pd}$ shows no precipitation phenomena, because it forms a complete solid solution in all atomic ratios [14]. On the other hand, precipitation can occur in the Au-Pt alloy due to the differences in solubility in each other at the temperatures for aging $\left(550^{\circ} \mathrm{C}\right)$ and solution-treatment $\left(950{ }^{\circ} \mathrm{C}\right)$ [14]. From the alloy composition, the precipitated phases $\left(\beta_{1}\right.$ and $\left.\beta_{2}\right)$ were believed to be Pt-concentrated phases, even though the lattice information was unclear due to XRD peak overlap. To confirm this, the specimen was analysed by FE-SEM and EDS.

\section{Microstructural changes}

Figure 4 shows FE-SEM images of $\times 300(1), \times 8,000(2)$ and $\times$ 60,000 (3) magnifications for the specimens solution-treated at $950{ }^{\circ} \mathrm{C}$ for $10 \mathrm{~min}$ (Fig. 4a), and aged at $550{ }^{\circ} \mathrm{C}$ for $30 \mathrm{~s}$ (Fig. 4b), 2 min (Fig. 4c), $100 \mathrm{~min}$ (Fig. 4d), 2,000 min (Fig. 4e) and 20,000 min (Fig. 4f). In the specimen solutiontreated at $950{ }^{\circ} \mathrm{C}$ for $10 \mathrm{~min}$ (Fig. 4a), an equiaxed structure of a single phase was observed. The lamellar-forming grain boundary reaction was progressed slightly. Such a grain boundary reaction must have occurred instantly during quenching after a solution treatment, considering the XRD results that revealed peak broadening within very short aging time (30 s).

In the specimens aged for $30 \mathrm{~s}$ (Fig. 4b), the grain boundary nano-sized precipitate grew towards the grain interior, and after further aging for $2 \mathrm{~min}$ (Fig. 4c), they grew slightly more, as marked by the arrows. By aging the specimen for $100 \mathrm{~min}$ (Fig. 4d), at which time the maximum hardness was obtained, lamellar structures composed of a precipitate and solutedepleted matrix coarsened apparently and replaced approximately half of the matrix, whereas no apparent change was observed in the grain interior. In the specimens aged for 2,000 min (Fig. 4e), the lamellar structure became much coarser, and the lamellar-forming grain boundary reaction was stopped without initiating a second grain boundary reaction which produces a much coarser lamellar structure. In addition, the fine grain interior precipitate was observed throughout the entire grain interior by microstructural coarsening. These changes decreased the hardness slightly
$(-15 \mathrm{HV})$, from the age-hardening curve shown in Fig. 2. After further aging for 20,000 min (Fig. 4f), the precipitate in the grain boundary and grain interior coarsened slightly more. Such a change resulted in an apparent decrease in hardness $(-50 \mathrm{HV})$.

The above result confirmed hardening by precipitation and the lamellar-forming grain boundary reaction. To characterise the relationship of the lamellar-forming grain boundary reaction with the change in hardness, the microhardness was measured again using a 25-gf load to obtain data separately in the grain interior (G.I) and grain boundary (G.B) region of the specimens aged for $2 \mathrm{~min}$ (Fig. 4c), $100 \mathrm{~min}$ (Fig. 4d) and 2,000 min (Fig. 4e). The results are listed in Table 2. In the specimen aged for $2 \mathrm{~min}$ (Fig. 4c), as shown in Table 2, each hardness value in the G.I and G.B precipitate was much higher than that of the single-phased solution-treated specimen (119 HV). Moreover, the hardness in the G.B precipitate was much higher than that in the G.I. Therefore, both the grain interior and grain boundary precipitate attributed to hardening, but the grain boundary precipitate comprising the fine lamellar structure caused more powerful hardening in the early stage of the aging process.

In the specimen further aged for 100 min (Fig. 4d), at which time the maximum hardness was obtained by measuring using a 300 -gf load, the precipitate at the grain boundary was coarsened slightly. This change, however, did not decrease the hardness in the grain boundary according to the data measured using the 25 -gf load. On the other hand, the hardness in the G.I increased to become similar to that of the G.B precipitate. Therefore, both the grain boundary and grain interior precipitate contributed to the maximum hardness in the intermediate stage of the aging process.

In the specimen aged for 2,000 min (Fig. 4e), at which time the hardness measured using a 300-gf load decreased slightly $(-15 \mathrm{HV})$, only the hardness in the G.B precipitate decreased slightly $(-20 \mathrm{HV})$ according to the data measured using a $25-$ gf load. This was expected from the apparent coarsening of the grain boundary precipitate. The coarsening of the microstructure also progressed in the grain interior slightly, but a high hardness was maintained. Therefore, in the later stage of aging process, microstructural coarsening and resulting softening occurred faster in the grain boundaries than in the grain interior.

Ohta et al. reported that the first and second grain boundary reaction produced a lamellar structure with different widths, resulting in hardening and softening, respectively, in the alloy composed of $48.78 \mathrm{Ag}-28 \mathrm{Pd}-12.04 \mathrm{Au}-9.12 \mathrm{Cu}$ (wt\%) [6]. In the present study, the formation of a lamellar structure at the grain boundaries occurred immediately as the hardening mechanism, and the subsequent slow increase in width of the lamellar structure resulted in softening without a second grain boundary reaction. Therefore, it is believed that the 
Fig. 4 FE-SEM images of $\times 300$ $(1), \times 8,000(2)$ and $\times 60,000$ (3) magnifications for the specimens solution-treated at $950{ }^{\circ} \mathrm{C}$ for $10 \mathrm{~min}\left(\right.$ a), and aged at $550^{\circ} \mathrm{C}$ for $30 \mathrm{~s}(\mathbf{b}), 2 \mathrm{~min}(\mathbf{c}), 100 \mathrm{~min}(\mathbf{d})$, 2,000 $\min (\mathbf{e})$ and $20,000 \mathrm{~min}(\mathbf{f})$
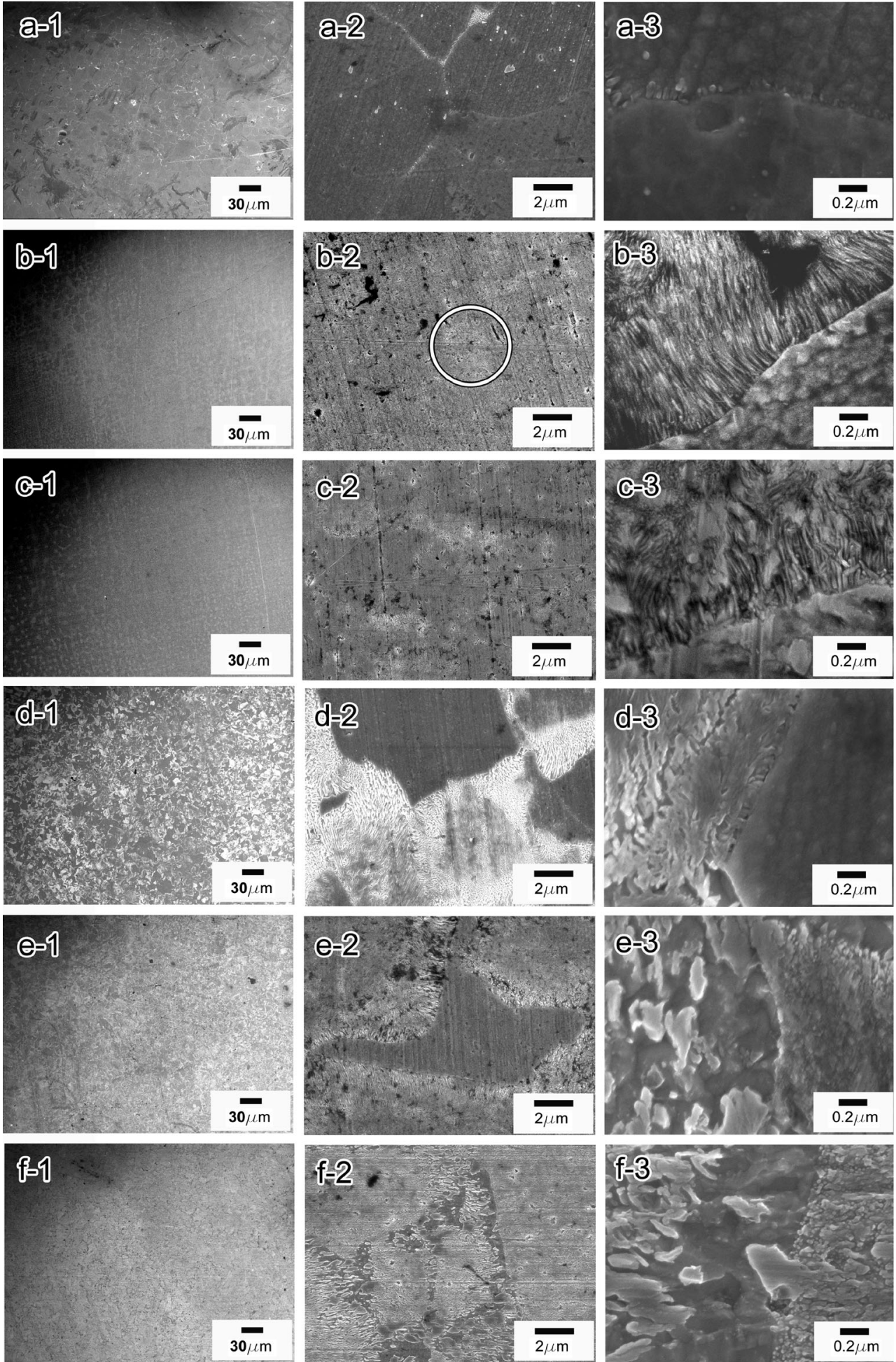

extremely fine nature of the lamellar structure supplied large amounts of inter-phase boundaries, which contain lattice strain by difference in lattice parameter between the solutedepleted Au-rich layer and the precipitated layer of the lamellar structure. Therefore, the subsequent microstructural coarsening that reduces the inter-phase boundaries results in softening, as has also been observed in various dental agehardenable alloys [18-21]. Considering the immediate lamellar formation, the restorations made by the Pt-added-Au-based metal-ceramic alloys can be strengthened easily during the firing process for porcelain by the introduction of a fine lamellar structure. 
Table 2 Vickers microhardness numbers (HV) measured with a 25-gf load in the grain interior (G.I) and grain boundary (G.B) precipitate of the specimens aged at $550{ }^{\circ} \mathrm{C}$ for various times

\begin{tabular}{llll}
\hline Aging time Region & $2 \mathrm{~min}$ & $100 \mathrm{~min}$ & $2,000 \mathrm{~min}$ \\
\hline G.I & $188.4( \pm 4.7)$ & $244.4( \pm 5.2)$ & $242.9( \pm 10.9)$ \\
G.B & $246.1( \pm 15.1)$ & $247.2( \pm 7.7)$ & $227.6( \pm 4.1)$ \\
\hline
\end{tabular}

Elemental distribution

The elemental distribution in the grain interior and grain boundary lamellar structure was observed by EDS for the specimens solution-treated and aged at $550{ }^{\circ} \mathrm{C}$ for $20,000 \mathrm{~min}$. Figure 5 presents FE-SEM images of the specimens solution-treated at $950{ }^{\circ} \mathrm{C}$ for $10 \mathrm{~min}$ (Fig. 5a, $\times 2,000$ magnification) and aged at $550{ }^{\circ} \mathrm{C}$ for 20,000 min (Fig. 5b, $\times 8,000$ magnification) for EDS point analysis. Table 3 lists the EDS results of the matrix and matrix layer $(\mathrm{M})$ and coarsened precipitate $(\mathrm{P})$ layer of the grain boundary lamellar structure, and the G.I region. In Table 3, the elemental distribution in the matrix of the solution-treated specimen (a-M) was similar to the alloy composition listed in Table 1. The minor ingredients (Sn, $\mathrm{Cu}, \mathrm{Ir}, \mathrm{Fe})$ were not detected by EDS.

In the solute-depleted matrix layer (b-M) of the grain boundary lamellar structure for the specimen aged at $550{ }^{\circ} \mathrm{C}$
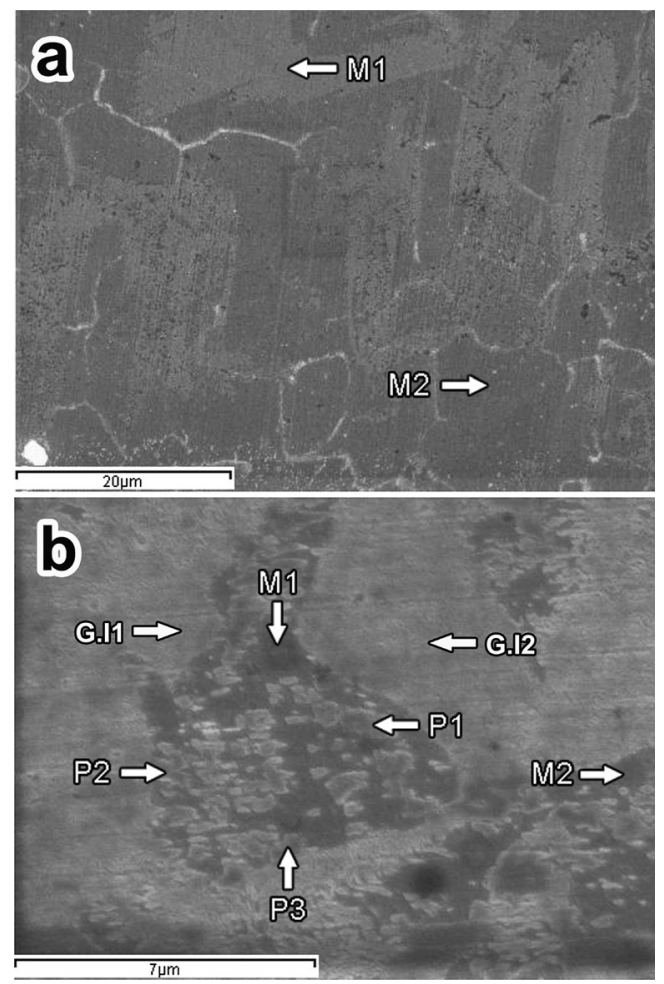

Fig. 5 FE-SEM images at $\times 2,000$ and $\times 8,000$ magnifications for EDS point analysis of the specimen solution-treated at $950{ }^{\circ} \mathrm{C}$ for $10 \mathrm{~min}$ (a) and aged at $550^{\circ} \mathrm{C}$ for $20,000 \mathrm{~min}(\mathbf{b})$, respectively for 20,000 min, the Au content increased compared to that of the solution-treated specimen (a-M). The Pt content decreased, and there was no apparent change in the $\mathrm{Pd}$ content. Minor ingredients (In, $\mathrm{Ag}, \mathrm{Sn}, \mathrm{Cu}, \mathrm{Ir}, \mathrm{Fe}$ ) were not detected. In the coarsened precipitate layer (b-P) of the grain boundary lamellar structure for the specimen aged at $550{ }^{\circ} \mathrm{C}$ for $20,000 \mathrm{~min}$, the Au content decreased to almost half of the value in the matrix (b-M), and the $\mathrm{Pt}$ content increased approximately ten times the value in the matrix (b-M), as can be expected from the binary phase diagram of the Au-Pt system which showed the solubility limit of $\mathrm{Au}$ and $\mathrm{Pt}$ in each other [14]. The minor ingredients, In and Sn, were concentrated in the precipitate region (b-P). Pd is completely soluble with $\mathrm{Au}$ at all atomic ratios but has a solubility limit with $\mathrm{Pt}$ [14]. On the other hand, in the present study, the Pd content was slightly higher in the Pt-concentrated region (b-P) than in the Pt-depleted region (b-M). This appears to be because Pd normally tends to form a stable phase with elements having a relatively low melting temperature, such as In and $\mathrm{Sn}$ [21]. In the G.I region for the specimen aged at $550{ }^{\circ} \mathrm{C}$ for $20,000 \mathrm{~min}$, the elemental distribution was similar to that of the single-phased matrix of the solution-treated specimen (a-M) due to the fine nature of the grain interior precipitates and solute-depleted matrix in the grain interior.

The above results were also revealed by EDS line analysis. Figure 6 shows the EDS line profile and FESEM image $(\times 8,500$ magnification $)$ of the specimen aged at $550{ }^{\circ} \mathrm{C}$ for $20,000 \mathrm{~min}$ after a solution-treatment. The elemental distribution of $\mathrm{Au}$ was opposite to that of $\mathrm{Pt}$, In and $\mathrm{Sn}$ in the coarsened precipitate layer and solutedepleted matrix layer of the grain boundary lamellar structure. The amount of $\mathrm{Pd}$ increased slightly in the precipitate region, whereas $\mathrm{Ag}, \mathrm{Fe}, \mathrm{Cu}$ and $\mathrm{Ir}$ were distributed relatively evenly in the solute-depleted matrix and precipitate region. Therefore, the Au-rich $\alpha_{1}$ phase comprising the solute-depleted matrix layer of the grain

Table 3 EDS analysis of the regions marked in Fig. 6 of the specimens solution-treated at $950{ }^{\circ} \mathrm{C}$ (a) and aged at $550{ }^{\circ} \mathrm{C}$ for $20,000 \mathrm{~min}$ (b)

\begin{tabular}{|c|c|c|c|c|c|c|c|}
\hline \multicolumn{2}{|c|}{ Region (at.\%) } & \multirow{2}{*}{$\begin{array}{l}\mathrm{Au} \\
73.88\end{array}$} & \multirow{2}{*}{$\begin{array}{l}\mathrm{Pt} \\
8.19\end{array}$} & \multirow{2}{*}{$\begin{array}{l}\mathrm{Pd} \\
15.67\end{array}$} & \multirow{2}{*}{$\begin{array}{l}\text { In } \\
2.26\end{array}$} & \multirow{2}{*}{$\frac{\mathrm{Ag}}{0}$} & \multirow{2}{*}{$\frac{\mathrm{Sn}}{0}$} \\
\hline a & M1 & & & & & & \\
\hline & M2 & 70.96 & 8.64 & 15.64 & 2.66 & 2.10 & 0 \\
\hline \multirow[t]{7}{*}{$\mathrm{b}$} & M1 & 81.50 & 2.59 & 15.91 & 0 & 0 & 0 \\
\hline & M2 & 82.15 & 2.43 & 15.42 & 0 & 0 & 0 \\
\hline & $\mathrm{P} 1$ & 48.59 & 23.08 & 16.73 & 6.93 & 1.92 & 2.75 \\
\hline & $\mathrm{P} 2$ & 48.11 & 21.02 & 17.72 & 9.17 & 0 & 3.98 \\
\hline & P3 & 46.84 & 23.56 & 17.09 & 9.57 & 0 & 2.94 \\
\hline & G.I1 & 72.34 & 9.24 & 15.78 & 2.64 & 0 & 0 \\
\hline & G.I2 & 73.85 & 9.55 & 14.04 & 2.56 & 0 & 0 \\
\hline
\end{tabular}



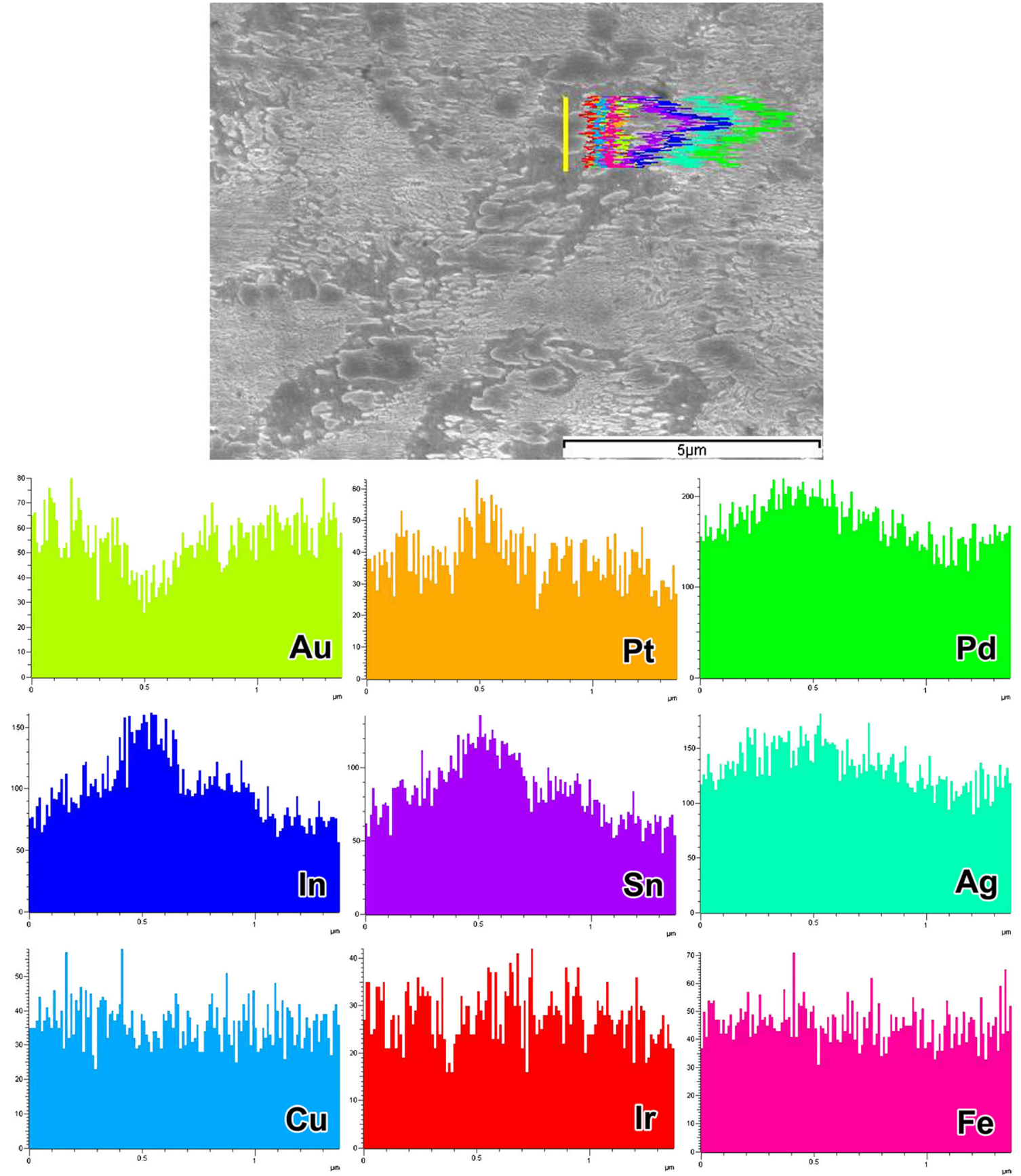

Fig. 6 FE-SEM images and EDS line profile of $\times 8,500$ magnification for the specimen aged at $550{ }^{\circ} \mathrm{C}$ for 20,000 min after the solution-treatment at $950{ }^{\circ} \mathrm{C}$ for $10 \mathrm{~min}$

boundary lamellar structure is a Pt-, In- and Sn-depleted phase compared to the parent Au-rich $\alpha$ phase, and the precipitated layer $\left(\beta_{1}\right)$ of the grain boundary lamellar structure is an In- and Sn-concentrated Au-Pt-rich phase. The precipitated phase in the grain interior was not clear by EDS. However, considering the XRD results which showed the existence of the $\beta_{2}$ phase having lattice parameter close to that of the $\mathrm{Pt}_{3} \mathrm{In}$ phase, the grain interior was possibly decomposed into the $\mathrm{Pt}_{3}$ In-based $\beta_{2}$ precipitates and Pt-, In-depleted Au-rich $\alpha_{2}$ matrix, resulting in apparent hardening in the grain interior.

XRD revealed that the lattice parameter from the superimposed diffraction peaks of the solute-depleted Aurich $\left(\alpha_{1}+\alpha_{2}\right)$ phases $\left(a_{200}=4.0231 \AA\right)$ was similar to that of the parent Au-rich $\alpha$ phase $\left(a_{200}=4.0222 \AA\right)$. This is because the precipitated $\beta_{1}$ and $\beta_{2}$ phases were formed by the coprecipitation of $\mathrm{Pt}$ and $\mathrm{In}$, which has a smaller and larger atomic size than $\mathrm{Au}$, respectively (distance of the closest 
approach, $D=2.7747 \AA$ for Pt, $D=3.2515 \AA$ for In and $D=$ $2.880 \AA$ for $\mathrm{Au}$ ) [16].

\section{Conclusions}

This study examined the relationship of the lamellar-forming grain boundary reaction with the change in hardness during the aging process of the Au-Pt-based metal-ceramic alloy composed of $76.6 \mathrm{Au}-9.9 \mathrm{Pt}-9.3 \mathrm{Pd}-1.7 \mathrm{In}-1.2 \mathrm{Ag}-0.56 \mathrm{Sn}$ (wt $\%$ ) with minor ingredients.

1. The phase decomposition of the parent Au-rich $\alpha$ phase occurred within a very short time (30 s) by aging at $550{ }^{\circ} \mathrm{C}$ after a solution-treatment at $950{ }^{\circ} \mathrm{C}$, which initiated the lamellar-forming grain boundary reaction.

2. Both the grain interior and grain boundary precipitate attributed to hardening, but the grain boundary precipitate comprising the fine lamellar structure caused more powerful hardening from the early stage of the aging process.

3. The alternate layer of the lamellar structure was composed of a Pt-, In- and Sn-depleted Au-rich $\alpha_{1}$ phase and a precipitated Pt-, In- and Sn-concentrated $\beta_{1}$ phase.

4. The extremely fine nature of the grain boundary lamellar structure supplied large numbers of inter-phase boundaries that contained lattice strain due to difference in lattice parameter between the $\alpha_{1}$ and $\beta_{1}$ phases, resulting in hardening.

Acknowledgments This research was supported by Basic Science Research Program through the National Research Foundation of Korea (NRF) funded by the Ministry of Education, Science and Technology (grant number: 2011-0010995).

Open Access This article is distributed under the terms of the Creative Commons Attribution License which permits any use, distribution, and reproduction in any medium, provided the original author(s) and the source are credited.

\section{References}

1. Anusavice KJ (2006) Phillips' science of dental materials, 11th edn. Saunders WB, Philadelphia, pp 621-654
2. German RM (1980) Hardening reactions in a high-gold content ceramo-metal alloy. J Dent Res 59:1960-1965

3. O'Brien WJ, Kring JE, Ryge G (1964) Heat treatment of alloys to be used for the fused porcelain technique. J Prosthet Dent 14:955-960

4. Leinfelder KF, O’Brien WJ, Ryge G, Fairhurst CW (1966) Hardening of high-fusing gold alloys. J Dent Res 45:392-396

5. Craig RG (1989) Restorative dental materials. The CV Mosby Co., St Louis, p 499

6. Ohta M, Hisatsune K, Yamane M (1975) Study on the agehardenable sillver alloy (3rd Report) III on the ageing process of dental Ag-Pd-Cu-Au alloy. J Jpn Soc Dent Appar Mater $16: 87-92$

7. Yasuda K, Ohta M (1980) Age-hardening characteristics of a commercial dental gold alloy. J Less-Common Metals 70:75-87

8. Yasuda K, Udoh K, Hisatune K, Otha M (1983) Structural change induced by ageing in commercial dental gold alloys containing palladium. Dent Mater 2:48-58

9. Hisatsune K, Hasaka M, Sosrosoedirdjo BI, Udoh K (1990) Agehardening behaviour in a palladium-based dental porcelain-fused alloy. Mater Charact 25:177-184

10. Yasuda K, Hisatsune K (1993) Microstructure and phase transformations in dental gold alloys. Gold Bull 26:50-66

11. Jeon GH, Kwon YH, Seol HJ, Kim HI (2008) Hardening and mechanisms in an Au-Ag-Cu-Pd alloy with In additions. Gold Bull 41: 257-263

12. Wise EM, Crowell W, Eash JT (1932) The role of the platinum metals in dental alloys II. Trans Met Soc AIME 99:363-412

13. Wise EM, Eash JT (1933) The role of the platinum metals in dental alloys III. Trans Met Soc AIME 104:276-307

14. Massalski TB (1990) Binary alloy phase diagrams, 2nd ed. ASM International, Materials park, pp 409-410 (Au-Pd), pp 414-416 (AuPt), pp 3033-3034 (Pd-Pt)

15. Hisatsune K, Tanaka T, Udoh K, Yasuda K (1977) Ageing reactions in a high carat gold alloy for dental porcelain bonding. J Mater Sci 8: 277-282

16. Culity BD (1978) Elements of X-ray diffraction, 2nd edn. AddisonWesley publishing Co., Inc., Massachusetts, pp 506-507

17. Villars P, Calvert LD (1985) Pearson's handbook of crystallographic data for intermetallic phases. American Society for Metals, Metals Park, p 2562

18. Hisatsune K, Otha M, Shiraishi T, Yamane M (1982) Age hardening in a dental white gold alloy. J Less-Common Metals 83:243-253

19. Udoh K, Hisatsune K, Yasuda K, Otha M (1984) Isothermal agehardening behavior in commercial dental gold alloys containing palladium. Dent Mater 3:253-261

20. Hisatsune K, Tanaka Y, Udoh K, Yasuda K (1997) Ageing reactions in a high carat gold alloy for dental porcelain bonding. J Mater Sci Mater Med 8:277-282

21. Kim HI, Park YH, Lee HK, Seol HJ, Shiraishi T, Hisatsune K (2002) Precipitation hardening in a dental low-gold alloy. Dent Mater 22:10-20 